\title{
Outcome of Twin Pregnancy in a Periurban Hospital
}

\author{
SARIA TASNIM ${ }^{1}$, F M ANAMUL HAQUE ${ }^{2}$, SAMEENA CHOWDHURY 3
}

\begin{abstract}
:
Objective: To determine the socio demographic characteristics, clinical presentation and obstetric outcome at delivery and immediate postpartum period of twin gestation in a periurban hospital

Material \& Methods: An observational study was conducted between January 2000 to December 2004 at Institute of Child and Mother Health. All twin pregnancy irrespective of gestational age admitted in the in-patient department of Institute of Child and Mother Health for delivery and also those undiagnosed cases found to have twin birth were enrolled in the study consecutively from January 2001 to December 2004. Data on socio-demographic factors, predisposing factors for twin gestation and obstetric characteristics was collected using a structured questionnaire. Hospital records were consulted for recording the investigation reports and management options. The outcome variables were maternal complications during antenatal, intranatal and immediate postnatal period, mode of delivery, birth weight and sex of newborn and fetal outcome. All twin pregnancies from the admitted obstetric patients were enrolled consecutively
\end{abstract}

Results: During the study period there were 11,185 deliveries and among them 107 were twin gestation. About $22 \%$ were primigravida, $78.5 \%$ multigravida, $27.1 \%$ were illiterate. Most common age group were $24-29$ years (39.4\%). Antenatal care was availed by $71 \%$ of patients and $27.1 \%$ twins were not diagnosed till delivery. Family history of twin on maternal side was present in $58.1 \%$ and $31.8 \%$ had history of taking oral contraceptive immediately before the pregnancy. Ovulation inducing agents were given to $8.3 \%$ of twin.

Presentations of fetus were both vertex $54.2 \%$, 1st vertex and second breech $16 \%$, and both breech $5.7 \%$. About $55.1 \%$ were admitted with labor pain, 6.5\% were undelivered second twin. Preterm birth was $27.2 \%$ and low birth weight of 1 st baby $79.6 \%$ and second baby $80.9 \%$ respectively. Mode of delivery was vaginal delivery of both fetus $41.6 \%$, caesarean section of both fetus $62.4 \%$, and caesarean for second twin $3.1 \%$. Same sex of both twins was found in $78 \%$ and male-male pair was $50 \%$. There was one stillbirth, one conjoined twin and perinatal death was $11.2 \%$ Complications encountered during perinatal period were severe abdominal pain 9.3\%, retained placenta in $7.3 \%$; and post partum hemorrhage in $4.6 \%$ cases.

Conclusion: Twin pregnancy is quite common and warrants specialized care during ante partum, intrapartum and postpartum period.

Key words: Twin, presentation, perinatal complication,

\section{Introduction:}

Twin pregnancy has aroused curiosity and attention for generations. In some traditional societies twins were believed to be supernatural origin and considered fragile and threatened by misfortunate ${ }^{1}$. Multiple pregnancies are recognized as associated with increased incidence of adverse pregnancy outcome with significant management challenges and require special medical care ${ }^{2}$. Low birth weight and prematurity are the main causes of perinatal mortality and malpresentation of one or both babies occurs in about $60 \%$ of twin pregnancies ${ }^{3}$. Studies have shown

1 Professor, Department of Obstetrics \& Gynaecology, Institute of Child and Mother Health. Bangladesh

2. Assistant Professor, Department of Obstetrics \& Gynaecology Institute of Child and Mother Health. Bangladesh

3. Professor and Head (Retd), Department of Obstetrics \& Gynaecology, Institute of Child and Mother Health. Bangladesh 
an 8 fold increase in the neonatal mortality between twins and singletons in Nepal and 5 times higher in Bangladesh ${ }^{4,5}$.

Twin gestation make up approximately $1 \%$ of all pregnancies, however, in some developed countries the incidence has increased ${ }^{3}$. In the United States, between 1980 and 1997, the twin gestation rate increased by $42 \%{ }^{6}$. In Canada multiple births increased from 18.2 to 25 per 1000 deliveries between 1974 to $1997^{7}$. The rising trend in multiple gestation, especially in higher order multiple gestation, has been attributed to the increased use of ovulation inducing agents, use of assisted reproductive technologies, and a shift toward bearing children at older maternal ages when multiple gestation are more likely to occur naturally ${ }^{7}$. It is said that as FSH levels start to increase around a decade before the onset of the menopause, women aged 35 or more may have multiple follicle growth. When these women have good quality oocytes, the chance to become pregnant with dizygotic twins is increased ${ }^{8}$.

Multiple pregnancies are recognized as high risk pregnancy that is associated with increased risk for both maternal and fetal morbidity and mortality ${ }^{9}$. Overall $55 \%$ of twin versus $10 \%$ singletons are born at $<37$ weeks and twins accounts for $10-12 \%$ of all preterm births ${ }^{10}$. Children born multiple births are more than six times likely to die during first year of life as children born singleton ${ }^{11}$.

Twinning rate appear to vary substantially across geographical areas and ethnicity with higher rates among black and lowest rate in $\mathrm{Asia}^{4}$. Study from Bangladesh and Nepal has shown a rate of 9 and 16.1 per 1000 pregnancies respectively ${ }^{4,5}$. Evidence from Bangladesh, rural India and Nepal shows that rates of twinning increase with increasing parity and it was highest among women 35 years and over 4 5,12.

The purpose of the study was to determine the socio demographic characteristics, clinical presentation and outcome at delivery and immediate postpartum of twin gestation in a periurban hospital.

\section{Method:}

This was a cross sectional observational study. All twin pregnancy irrespective of gestational age admitted in the in-patient department of Institute of Child and Mother Health for delivery and also those undiagnosed cases found to have twin birth was enrolled in the study consecutively from January 2001 to December
2004. Data on socio-demographic factors, predisposing factors for twin gestation and obstetric characteristics was collected using a structured questionnaire. Hospital records were consulted for recording the investigation reports and management options. The outcome variables were maternal complications during antenatal, intranatal and immediate postnatal period, mode of delivery, birth weight and sex of newborn and fetal outcome. Data was analyzed using SPSS program.

\section{Results:}

During the study period total 11,185 deliveries took place in the hospital, among them twin delivery was 107 , so the prevalence was $0.95 \%$. Mean age of the patients was $24.9 \pm 4.4 \mathrm{yrs}$ (range $16-39$ years), and $77.5 \%$ belonged to $20-30$ years, $67.2 \%$ reside in own house, $41 \%$ completed primary school, $21.4 \%$ had consanguinous marriage and $35.5 \%$ had twins in the family (Table I). Majority were multipara (78.5\%), $71 \%$ had antenatal care in current

Table-I

Sociodemographic profile of the respondents

\begin{tabular}{lcc}
\hline Characteristics & Number & Percentage \\
\hline Age & & \\
$<20$ yrs & 12 & 11.2 \\
$20-30$ yrs & 83 & 77.5 \\
Resides in own house & 72 & 67.2 \\
Resides in a rented house & 35 & 32.7 \\
Income generation by self & 12 & 11.2 \\
Illiterate & 29 & 27.1 \\
Completed primary school & 44 & 41 \\
Completed secondary school & 34 & 31.7 \\
H/o consanguineous marriage & 21 & 21.4 \\
\hline
\end{tabular}

pregnancy, $27.1 \%$ were first diagnosed at the time of delivery and $55 \%$ admitted with labor pain (TableII). Most common complication during pregnancy was pain in abdomen $58.8 \%$, next was high blood pressure $30.8 \%$ (Table-III). Over half (54.2\%) were vertexvertex presentation, next was first vertex and second breech (Table-IV). Preterm labour (29-36 weeks) was $27.2 \%, 5.6 \%$ ended up as abortion and $6.5 \%$ were undelivered second twin (Table-V). Mean birth weight $1.9 \pm 0.78$ and $1.8 \pm 0.73 \mathrm{Kg}$ for $1 \mathrm{st}$ and $2 \mathrm{nd}$ baby respectively and low birth weight was $80 \%$ (Table$\mathrm{VI}$ ). Most common mode of delivery was caesarean section $62.4 \%$ ( Figure 1). Sex distribution shows $78 \%$ of the pair belonged to same sex and ratio of 
Table-II

Distribution according to Obstetric characteristics

\begin{tabular}{lcc}
\hline Characteristics & Number & Percentage \\
\hline Primigravida & 23 & 21.5 \\
Multi gravida & 84 & 78.5 \\
Antenatal check up in current pregnancy & 76 & 71 \\
Diagnosis made by USG before admission & 78 & 72.9 \\
Diagnosed at the time of delivery & 29 & 27.1 \\
H/o taking ovulation induction drug & 10 & 9.3 \\
Admission with labor pain & 58 & 54.7 \\
Admission for delivery without labor pain & 29 & 27.4 \\
H/O Twin in the family & 38 & 35.5 \\
Use of oral contraceptive immediately before pregnancy & 34 & 31.8 \\
\hline
\end{tabular}

Table-III

Distribution according Complication during pregnancy

\begin{tabular}{lcc}
\hline Complication & No & $\%$ \\
\hline Excessive vomiting & 26 & 24.2 \\
Pain in abdomen & 63 & 58.8 \\
High BP & 33 & 30.8 \\
APH & 5 & 4.6 \\
Breathlessness & 23 & 21.4 \\
PET & 15 & 14.0 \\
Others & 8 & 7.4 \\
\hline
\end{tabular}

Table-IV

Distribution according to Presentation of fetuses $(n-107)$

\begin{tabular}{lcc}
\hline Presentation & No & $\%$ \\
\hline $1^{\text {st }}$ VX \& $2^{\text {nd }}$ Breech & 17 & 15.9 \\
Both Vertex & 58 & 54.2 \\
$1^{\text {st }}$ Breech \& $2^{\text {nd }}$ VX & 16 & 14.9 \\
Both Breech & 6 & 5.7 \\
Other & 8 & 7.6 \\
\hline
\end{tabular}

Table-V

Distribution according to Pregnancy outcome

\begin{tabular}{lcc}
\hline Characteristics & Number & Percentage \\
\hline Abortion & 6 & 5.6 \\
Preterm labour (29-36 weeks) & 28 & 27.2 \\
Term labour & 75 & 72.8 \\
Undelivered second twin & 8 & 6.5 \\
\hline
\end{tabular}

Table-VI

Distribution according to birth weight

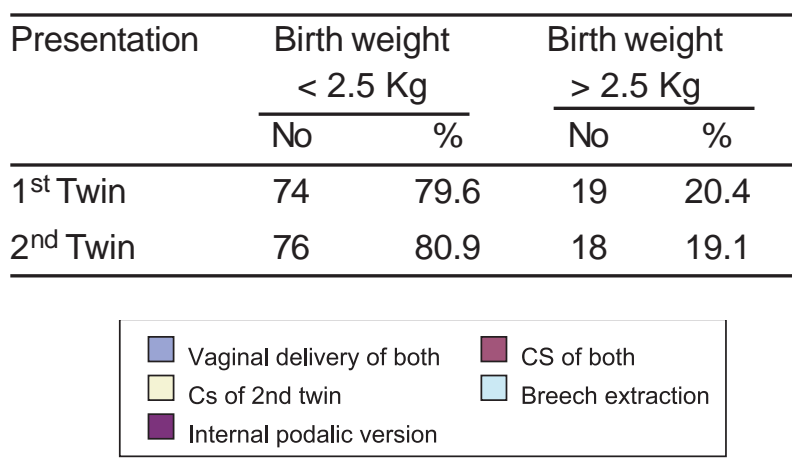

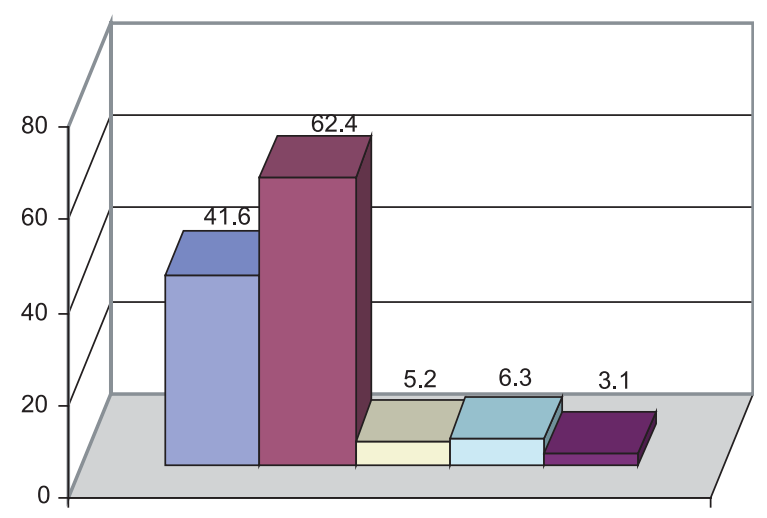

Fig.-1: Percent Distribution according to mode of delivery

male to female was 1.5: 1 and 1.65:1 for first and second twin respectively (Figure 2 ). There was one stillbirth, one conjoined twin and twelve perinatal death (11.2\%). Breast milk was given as first food in $86.9 \%$ and $85 \%$ were exclusively breastfed at the time of discharge (Table-VII). Common post natal complications were severe abdominal pain 9.3\%, 7.3\% 
had retained placenta, post partum hemorrhage 4.6\%, and urinary complain in 7.3\% (Table-VIII).

Table-VII

Distribution according to fetal outcome

\begin{tabular}{lcc}
\hline Outcome & No & $\%$ \\
\hline Healthy New born & 93 & 86.9 \\
Still Birth & 1 & 0.65 \\
Perinatal death & 12 & 11.2 \\
Breast milk given as first food & 93 & 86.9 \\
EBF at discharge & 91 & 85 \\
Conjoined twin & 1 & 0.65 \\
\hline
\end{tabular}

Table-VIII

Distribution according to early post natal complication

\begin{tabular}{lcc}
\hline Complication & Number & $\%$ \\
\hline Sever Pain in abdomen & 10 & 9.3 \\
Retained Placenta & 8 & 7.3 \\
PPH & 5 & 4.6 \\
Fever> 100.40 F & 3 & 2.8 \\
Urinary complain & 8 & 7.3 \\
Wound infection & 2 & 1.8 \\
Bowel problem & 2 & 1.8 \\
Breast problem & 4 & 3.7 \\
Others & 7 & 6.5 \\
\hline
\end{tabular}

\section{Discussion:}

The prevalence of twinning in this study was 9.5 per 1000 delivery which is little bit higher than that reported from previous study in Bangladesh that shows the incidence of twin birth over a period of 16 years vary between 7.8 and 11.2 per thousand live births ${ }^{4}$. It is said that twinning rate in hospital based studies may be higher than would be observed in the population since twins would be more likely to deliver at hospitals ${ }^{5}$. Twin rate in rural community of India and Thailand was reported to be 9.01 and 8.6 per 1000 delivery respectively ${ }^{12,13}$. In Denmark between 1980-94 the twinning rate was reported to be 12.1 per 1000 pregnancies and there was history of use of ovulation induction and advanced reproduction technique in about a quarter of multiple births ${ }^{14}$.

The age distribution of our study shows maximum twin pregnancy belonged to 20-30 years indicating social norm of early marriage and childbearing. According to Bangladesh Demographic and Health Survey 2004 data, about $2 \%$ of children are of multiple births , two thirds (63\%) of the births to aged 13-24 years and $31 \%$ to mother aged $25-34$ years $^{15}$ . Some studies has found that twinning among mothers over 35 years was 2 times higher than for mothers younger than 20 years $^{16}$. Evidence from Bangladesh shows twinning rate among mothers over 35 years was about 3 times higher than for mothers younger than 20 years ${ }^{5}$. In India twinning rate between 30-34 years was 10 times higher than for mothers younger than 20 years $^{12}$.

In our study $72.9 \%$ were diagnosed antenatally through USG indicating better availability and awareness to use the technology. Perinatal mortality was found to be higher among the group in which diagnosis of twin was not done during antenatal period indicating need for special preparation for conducting twin deliveries ${ }^{12}$.

Mode of delivery in twin gestation represents a dilemma as twin are at a higher risk than singletons for preinatal morbidity and mortality ${ }^{9,13}$.The greatest danger exist for the second twin especially those in a non vertex presentation ${ }^{16}$. Prior to 1970 standard obstetric practice was management of twin labor according to the presentation of the first twin with delivery maneuver appropriate to deliver second twin 17. In 1976 it was recommended that to improve neonatal outcome caesarean delivery of all twins should be performed if one twin was in non vertex presentation $^{17}$. The SOGC and ACOG both recommend vaginal delivery for non vertex second twin as long as criteria for vaginal breech delivery are met ${ }^{17}$. Some studies have demonstrated that there was no significant difference in neonatal morbidity or mortality between vaginally delivered and cesarean group for non vertex second twin ${ }^{18}$.

Presentation at delivery of twins was mostly in vertexvertex presentation which was similar to the previous studies $^{13}$. However, Caesarean section was the most common route of delivery and this finding was similar to other studies9. In a recent study from Austria $78 \%$ had vaginal birth of both twins, $17 \%$ had caesarean section for both and in 5\% women the second twin had to be delivered by caesarean section after vaginal delivery of first twin ${ }^{18}$. A policy of planned CS may result in a reduced incidence of a low 5 minute Apgar score when twin A is breech. However, there is also higher risk of respiratory distress syndrome and transient tachypnoea in newborn delivered by CS than in those delivered 
vaginally ${ }^{17}$. Twins with vertex -breech presentation delivered by caesarean-caesarean had a lower neonatal mortality compared to those delivered vaginal-vaginal (1.6 vs. 2 per 1000 twin live births) respectively ${ }^{19}$.

Low birth weight was the most common neonatal complication (80\%) which is much higher than the study from Thailand $(62.3 \%)^{13}$. It has been shown that preterm birth and low birth weight is significantly higher in twin pregnancy of women aged 25-29 years than in women aged 35 years or older ${ }^{20}$. So the increased low birth weight might be a reflection of poor maternal nutritional status and younger age group.

\section{Conclusion:}

Twin pregnancy is common among multipara and associated with low birth weight infants, high rate of caesarean section and perinatal mortality. It warrants a vigilant care for early recognition during prenatal visits and management by adequately trained personnel during antenatal, intranatal and postpartum period for better outcome.

\section{References:}

1. Picaud A, Nlome R, Oguwet-Igumua, Faye A, Mba-Allo L. Perinatal and maternal risk of multiple[le pregnancies. Revue Francaise De Gynecologic Etd Obstetrique 1989; 84 (5) 381382

2. Ananth CV, Joseph KS, Demissie K, Vintzileos AM. Trends in twin preterm birth subtypes in the United States, 1989 through 2000: impact on perinatal mortality. Am. J. Obstet. Gynecol. 2005; 193: 1076-82.

3. Boggers KA, Chisalm C A. Delivery of the non vertex second twin: a review of the literature. Obstet Gynaecol Surv 1997; 52 : 728-35.

4. Katz J, West K P Jr, Khatry S K, LeClerq, S C , Pradhan EI K, and Shrestha. S R Twining rates and survival of twins in rural Nepal. International Journal of Epidemiology 2001; 30:802-807

5. Razzaque A, Ahmed K, Wai, Twining rates in a rural area of Bangladesh. Hum Biol 1990;62:505-14
6. Tarter J G, Khoury A,. Barton J R, Jacques D L., and Bha M. Demographic and obstetric factors influencing pregnancy outcomes in twin gestation. Am J Obstet Gynecol 2002; 186:910-2

7. Joseph K S, Alexander C A, Linda D, Vincer M $\mathrm{J}$, Arrison B A. Causes and consequences of recent increases in preterm birth among twins. Obstet Gynecol 2001; 98: 57-64.

8. Beemsterboer SN, Homburg R, Gorter NA, Schats R, Hompes PGA, Lambalk CB. The paradox of declining fertility but increasing twinning rates with advancing maternal age. Hum Reprod (2006) 21:1531-1532.

9. Conde-Agudelo A, Belizan JM, Lindmark G. Maternal morbidity and mortality and mortality associated with multiple gestations. Obstet Gynecol 2000; 95: 899-904.

10. Kogan MD, Alexander GR, Kotelchuck M, MacDorman MF, Buckens P. M artin JA et al. Trends in twin birth outcomes and prenatal care utilization in the United States 1981-1997, JAMA 2000:284:335-41

11. Hong R. Effect of multiple births on infant mortality in Bangladesh. Journal of Paediatrics and Child Health 2006 ; 42:630-635

12. Mahesh Satija, Sarit Sharma, R. K. Soni, R. K. Sachar, and G. P. I. Singh. Twinning and Its Correlates: Community-Based Study in a Rural Area of India. Human Biology 2008; 80 (6):611621. doi: 10.3378/1534-6617-80.6.611

13. Chittacharoen A, Singhakun D, Israngura N. Ayudhya N. Pregnancy Outcome of Twin Pregnancy in Ramathibodi Hospital. J Med Assoc Thai 2006; 89 Suppl. 4: 576-80.

14. Westergaard T, Wohlfahrt J, Aaby P, Melbye M. Population based study of rates of multiple pregnancies in Denmark 1980-94. BMJ 1997; 314: 775-779.

15. Bangladesh Demographic and health survey 2004. National Institution of Population research and Training 2005. Dhaka. 
16. Schupp T R, Miyadahira S, KahhaleS,Zugaib $M$. Management of twin pregnancy in a university hospital: a 6 year study Rev Hosp Clin 2000; 55(4): 137-144.

17. Barrett J. Bocking A. The SOGG consensus statement on management of twin pregnancies (part 1). J SOGC 2000;91:519-32

18. Radisic B V, Pristauz G, Haas J, Glulani A, Tamussino K, Boder A, Lang U, Schlembach D. Neonatal outcome of second twins depending on presentation and mode of delivery. Twin Res Hum Genet 2007; 10 (3): 521-7.

19. Kontopolus EV, Ananth C V, Smulien J C, Vintzileos A M. The influence of mode of delivery on twin neonatal mortality in the US: variance by birth weight discordance. Am J Obstet Gynecol 2005; 192: 252-6.

20. Delbaere I; Verstraelen H; Goetgeluk S; Martens G, Derom C; Bacquer D D, Backer G D; Temmerman M. Perinatal. Outcome of Twin Pregnancies in Women of Advanced Age Hum Reprod. 2008; 23(9):2145-2150. 